\title{
The need for geodetic control to monitor the displacements of buildings and structures
}

\author{
Vladimir Simonjan ${ }^{1,}$ and Svetlana Shendyapina ${ }^{1}$ \\ ${ }^{1}$ Moscow State University of Civil Engineering (MGSU), 26, Yaroslavskoye Shosse, Moscow, Russia
}

\begin{abstract}
The article overviews the main reasons of settlings and other deformations of constructed and operated buildings and structures. The authors consider geodetic control methods of the deformations using various examples. Some recommendations on their monitoring are given. The deformations are often take place because of unsatisfactory engineering surveys. Therefore, these problems are urgent not only for designers and builders but also for engineering surveyors.
\end{abstract}

\section{Introduction}

In most cases, it is believed that the influence of a number of environmental factors on the geometric characteristics of buildings and structures is negligible, so they are not always taken into account. However, this assumption is not always valid. Obtaining real quantitative values characterizing changes in the geometry of buildings and structures under the influence of environmental factors, forecasting and accounting for these values during construction and operation are very important to ensure and maintain the compliance of these facilities with design parameters and, accordingly, their safety. The article discusses the impact of various environmental factors on constructed and operated buildings and structures, which have a certain effect on their geometric parameters. The authors draw the attention of specialists to the optimal solution to these problems. Deformations often occur due to unsatisfactory engineering surveys. Therefore, all these questions are relevant not only for designers and builders but also for surveyors.

In the general case, spatial displacements of buildings and structures occur both during their construction and during their operation. Such displacements are called deformations, which can be quantified in three-dimensional space along the $X, Y$, and $H$ axes. The displacement in the horizontal plane along the $X$ and/or $Y$ axes is called shear, and in the vertical plane along the $H$ axis - settling or rise.

To characterize some of the features of spatial displacements, widely known different

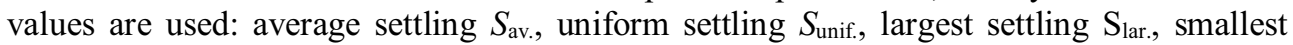
settling $S_{\mathrm{sm}}$, difference in uneven settlings $\Delta S$, relative difference of settlings $\Delta S_{\text {rel., }}$, relative deflection $V_{\text {def }}$ or hogging $V_{\text {hog }}$, longitudinal heeling $K_{\text {long. }}$ lateral heeling $K_{\text {lat. }}$ [1, 2].

\footnotetext{
${ }^{*}$ Corresponding author: angela-1309.m@yandex.ru
} 
Along with settlings, in a number of cases, individual parts of the building rise, which can be characterized by values similar to those for settlings, but having the opposite sign.

Various geophysical fields (gravitational, magnetic, electric, seismic, etc.) affect structures. Gravity largely determines the mechanical stresses and deformations of the structure foundations. Construction of structures, excavation of underground workings and various earthworks lead to deformation of structures and to uneven settling of the entire built-up area. Seismic safety monitoring based on observations of vertical displacements of a given territory should ensure the safety of buildings and structures. For this, it is proposed to carry out an appropriate forecast with a certain probability [3].

Displacements of buildings and structures also occur under the influence of human activity [4]. For example, as a result of the construction of surface facilities, conducting underground workings and various earthworks, deformations of structures and uneven settlings of the entire built-up area occur. Settlings of industrial buildings also occur during vibrations of machines and mechanisms located in them. So, during three years of observing the settlings of a frame-type building with a size of $20 \times 20 \mathrm{~m}$, settlings of its individual parts up to $50 \mathrm{~mm}$ in size was revealed, which led to the appearance of cracks in the walls of the shop [5].

\section{Materials and methods}

Over the past years, the number of storeys has increased, the spans of buildings and structures have increased, multi-storey complexes with complex structural solutions have appeared. The seismic resistance of such objects is not regulated by existing standards. The share of such objects is small, but they have a high level of responsibility and a large number of people is concentrated there.

In [6], it is recommended to take into account the deformation values of concrete hardening in natural climatic conditions. Deformations occur due to shrinkage and expansion of hardening concrete in its different layers. With a concrete thickness of $0.6 \mathrm{~m}$, shrinkage deformations reach $0.25 \mathrm{~mm}$ or more. The possibility of deformations of concrete during its curing must be taken into account when measuring the displacement of building parts. These deformations should also be taken into account when laying geodetic marks in hardening concrete.

Studies of the stability of the leveling network in St. Petersburg [7] have shown that the main types of displacements of ground benchmarks are raising (44\%) and lowering (35\%). The average rate of rising of ground marks for 23 years is $2.2 \mathrm{~mm} /$ year, and the rate of lowering is $0.44 \mathrm{~mm} /$ year. The maximum displacement of the ground benchmarks was plus $577 \mathrm{~mm}$ over 23 years, the maximum displacement of the wall benchmark was minus 360 $\mathrm{mm}$ over 45 years. The main reason for rising is frost heaving, the main reason for lowering is the insufficient bearing capacity of the foundation soils.

In Moscow, over 14 years, more than $45 \%$ of geodetic benchmarks have changed their marks by more than $10 \mathrm{~mm}$. To maintain the city's leveling network at the level of modern requirements, it is necessary to conduct re-leveling. The frequency of such leveling depends on the rate of change in the altitude position of geodetic signs and the requirements for the accuracy of their position.

In 1980, the repeated leveling of the network of 20 deep and 45 fundamental benchmarks laid down in 1977 on the territory of Moscow showed that the territory of the city is experiencing both ascending (up to plus $2 \mathrm{~mm} /$ year) and descending (up to minus 3 $\mathrm{mm} /$ year) tectonic movements of the earth's crust [8].

When monitoring large hydraulic structures, reservoirs, dams, tunnels, it is recommended to take into account the maps of the rates of vertical movements of the earth's surface, published in 1958 and updated in 1963 [9]. According to these maps, the 
western part of the territory of Russia is divided into zones of rising (by about plus 10 $\mathrm{mm}$ /year) and lowering (by about minus $4 \mathrm{~mm} /$ year). Errors in determining the speed of movement of the earth's surface are in the range of 1.5-2.3 mm/year.

Practice has shown that the need to observe the displacements and deformations of buildings and structures under construction and their parts arises not only in order to improve design solutions, but also to quantify these displacements for their subsequent consideration when performing layout work, assembling structures and equipment, as well as when assessing the functional performance of the constructed facilities.

In a number of methodological documents, it is recommended to observe the settlings of buildings when:

- constructing buildings over 18 floors;

- changing the reference of the building (without additional geological surveys of the foundation soil);

- erecting buildings on filled soil;

- constructing tower-type structures with a height of more than $50 \mathrm{~m}$.

It is advisable to carry out observations of foundations for equipment of large mass, especially after the end of its installation, in case of temperature changes due to the operation of the equipment, when the clay base of the foundations is soaked or accidentally frozen. Such conditions can occur during the operation of equipment for nuclear and hydroelectric power plants.

\section{Results}

It is known that, in addition to settlings, building structures undergo deformations as a result of temperature effects $[10,11]$. Under the influence of these deformations, the points of buildings are displaced, reaching significant values during the construction of high-rise buildings. They distort the results of geodetic measurements (for example, when transferring heights to the upper mounting horizons). For example, to determine the degree of influence of temperature deformations of a building on the accuracy of geodetic measurements, special studies were carried out in Moscow during the construction of a 16storey panel-block 207-apartment residential building with walls made of expanded clay concrete products. Empirical displacements of its points were studied due to changes in the temperature of the walls. For this purpose, special marks were installed on the 2nd, 7 th and 14th floors. To determine the displacement values, the method of trigonometric and geometric leveling was used.

Trigonometric leveling was performed using the theodolite T2, which was centered on geodetic marks located at a distance of 50 meters from the building. These marks were located at the ends of the base, from which the exact distances to all marks located on the wall of the building were determined by the method of intersections.

Geometric leveling was performed using the level L2 with an invar dashed rod and a vertically suspended measuring tape. In total, eight observation cycles were carried out with an increase in temperature from 0 to $16^{\circ} \mathrm{C}$. The observations lasted three months. The significance of the differences between the empirical and normal distributions was established using the Pearson's chi-squared test. It turned out to be less than 0.95 . Consequently, the hypothesis about the normal distribution of the displacements of the points of the building was not confirmed. This means that temperature influences lead to systematic point shifts. Correlation analysis showed that the relationship between the latter and the temperature $t$ and the number of floors $Z$ is very significant. For the probabilistic displacements of points of the building $S_{t}(\mathrm{~mm})$, depending on changes in its temperature $t$, the following empirical equations were obtained:

for the lower 5 floors: 


$$
S_{t}=-0.618+0.162 t+0.0006 t^{2}
$$

for the upper 7 floors:

$$
S_{t}=+0.392+0.211 t-0.0082 t^{2}
$$

for 12 floors:

$$
S_{t}=-0.242+0.380 t-0.0081 t^{2} \text {. }
$$

As a result of comparing the correlation coefficients characterizing the relationship between the displacements of the points of the building and its temperature, it was found that their values for 5-, 7- and 12-storey parts differ from each other. Consequently, the displacements of the points of the building depend not only on the temperature of its walls $t$, but also on the number of floors $Z$. To identify the relationship between these values, an empirical multiple correlation equation was found:

$$
S_{t}=-6.62+0.47 t+0.37 Z+0.015 t Z
$$

\begin{tabular}{|c|c|c|c|c|c|c|c|c|c|c|c|}
\hline \multirow{8}{*}{$\begin{array}{c}\text { Mark or } \\
\text { benchmark } \\
\text { number }\end{array}$} & \multicolumn{11}{|c|}{ Cycle number } \\
\hline & 1 & \multicolumn{2}{|c|}{2} & \multicolumn{2}{|c|}{3} & \multicolumn{2}{|c|}{4} & \multicolumn{2}{|c|}{5} & \multicolumn{2}{|c|}{6} \\
\hline & \multicolumn{11}{|c|}{ Observation date } \\
\hline & 01.08 .75 & 04.05 & & 06.0 & & 03.1 & & 31.0 & & 10. & \\
\hline & \multicolumn{11}{|c|}{ Number of erected floors of the building } \\
\hline & 1 & 5 & 9 & 13 & 20 & 25 & & & & & \\
\hline & \multicolumn{11}{|c|}{ Height $H$ and settling $S$} \\
\hline & $\mathbf{H}, \mathbf{m}$ & $\mathbf{H}, \mathbf{m}$ & $\begin{array}{l}\mathbf{S}, \\
\mathbf{m}\end{array}$ & $\begin{array}{c}\mathbf{H}, \\
\mathbf{m}\end{array}$ & $\begin{array}{l}\mathbf{S}, \\
\mathbf{m}\end{array}$ & $\begin{array}{l}\mathbf{H}, \\
\mathbf{m}\end{array}$ & $\begin{array}{l}\mathrm{S}, \\
\mathbf{m}\end{array}$ & $\begin{array}{l}\mathbf{H}, \\
\mathbf{m}\end{array}$ & $\begin{array}{l}\mathbf{S}, \\
\mathbf{m}\end{array}$ & $\begin{array}{l}\mathbf{H}, \\
\mathbf{m}\end{array}$ & $\begin{array}{l}\mathbf{S}, \\
\mathbf{m}\end{array}$ \\
\hline M10 & 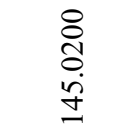 & 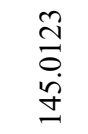 & $\stackrel{T}{T}$ & $\begin{array}{l}\circ \\
8 \\
8 \\
\dot{1} \\
\stackrel{1}{ \pm}\end{array}$ & $\underset{+}{\stackrel{+}{0}}$ & $\frac{\dot{0}}{0}$ & ' & $\begin{array}{l}\frac{m}{\sigma} \\
\text { à } \\
\dot{J}\end{array}$ & 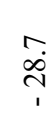 & $\begin{array}{l}8 \\
\infty \\
\circ \\
\dot{J}\end{array}$ & $\stackrel{0}{\dot{q}}$ \\
\hline M11 & 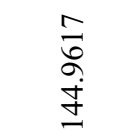 & 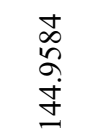 & $\underset{i}{\stackrel{m}{i}}$ & $\begin{array}{l}\circ \\
\stackrel{2}{a} \\
2 \\
\dot{J} \\
\pm\end{array}$ & $\vec{i}$ & 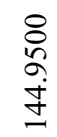 & $\stackrel{7}{\overline{1}}$ & 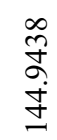 & $\frac{9}{1}$ & $\begin{array}{l}\text { oे } \\
\text { ó } \\
\text { J }\end{array}$ & $\stackrel{\infty}{\infty}$ \\
\hline M12 & $\begin{array}{l}\text { న̆ } \\
\hat{\sigma} \\
\dot{J} \\
\text { J }\end{array}$ & 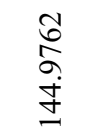 & $\ddot{\varphi}_{i}$ & $\begin{array}{l}\hat{\sigma} \\
\stackrel{a}{a} \\
\dot{J}\end{array}$ & $\stackrel{n}{i}$ & 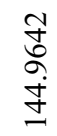 & $\stackrel{0}{i}$ & $\begin{array}{l}\dot{\sigma} \\
\stackrel{n}{ } \\
\dot{J} \\
\pm\end{array}$ & $\stackrel{\infty}{\frac{\infty}{1}}$ & $\begin{array}{l}\text { f } \\
\text { g } \\
\text { J }\end{array}$ & $\stackrel{n}{\stackrel{n}{*}}$ \\
\hline M13 & $\begin{array}{l}\Xi \\
\hat{\sigma} \\
\dot{J} \\
\pm\end{array}$ & $\begin{array}{l}\text { すे } \\
\text { مे } \\
\text { J }\end{array}$ & $\stackrel{T}{T}$ & 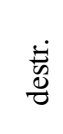 & ' & ' & ' & ' & ' & ' & ' \\
\hline M14 & $\begin{array}{l}\stackrel{n}{\hat{2}} \\
\infty \\
\dot{J} \\
\dot{J}\end{array}$ & $\begin{array}{l}0 \\
2 \\
\infty \\
\dot{J} \\
\dot{J}\end{array}$ & $\frac{9}{T}$ & $\begin{array}{l}\vec{\infty} \\
\infty \\
\dot{J} \\
\dot{J}\end{array}$ & $\begin{array}{l}0 \\
\stackrel{+}{+}\end{array}$ & $\begin{array}{l}i n \\
\infty \\
\infty \\
\dot{J} \\
\dot{J}\end{array}$ & $\stackrel{\infty}{\underset{7}{*}}$ & $\begin{array}{l}m \\
\infty \\
\infty \\
\dot{J} \\
\dot{J}\end{array}$ & 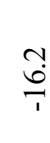 & $\begin{array}{l}\hat{\delta} \\
\infty \\
\dot{J}\end{array}$ & $\begin{array}{l}\infty \\
\stackrel{\overbrace{}}{1}\end{array}$ \\
\hline
\end{tabular}

with an error $m_{S t}=-3.4 \mathrm{~mm}$.

Table 1. The results of observations of the vertical displacements of the building and its parts. 


\begin{tabular}{|c|c|c|c|c|c|c|c|c|c|c|c|}
\hline M15 & 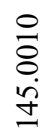 & 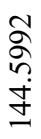 & $\stackrel{\sim}{\sim}$ & $\begin{array}{l}\infty \\
8 \\
8 \\
0 \\
\stackrel{y}{ \pm}\end{array}$ & $\begin{array}{l}\infty \\
\stackrel{\varphi}{i}\end{array}$ & $\begin{array}{l}\stackrel{2}{ } \\
\stackrel{\infty}{ } \\
\dot{ \pm}\end{array}$ & $\stackrel{F}{\bar{F}}$ & 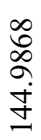 & $\frac{\infty}{\dot{ \pm}}$ & 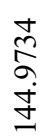 & $\underset{\sim}{\infty}$ \\
\hline M16 & \begin{tabular}{l}
$\mathscr{2}$ \\
$\delta$ \\
8 \\
$\dot{y}$ \\
\cline { 1 - 1 }
\end{tabular} & $\begin{array}{l}\text { 吉 } \\
\text { 亏े } \\
\stackrel{J}{ \pm}\end{array}$ & $\vec{r}$ & $\begin{array}{l}\stackrel{0}{2} \\
\text { } \\
\dot{J} \\
\dot{J}\end{array}$ & $\frac{n}{1}$ & 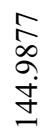 & $\stackrel{\infty}{\underset{i}{T}}$ & $\begin{array}{l}\text { ț } \\
\stackrel{2}{ } \\
\stackrel{J}{ \pm}\end{array}$ & $\vec{\sim}$ & $\begin{array}{l}\vec{N} \\
\hat{a} \\
\dot{J}\end{array}$ & $\begin{array}{l}+ \\
\stackrel{\infty}{\sim} \\
\stackrel{1}{1}\end{array}$ \\
\hline M17 & 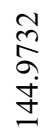 & \begin{tabular}{l}
$\stackrel{a}{\hat{a}}$ \\
$\vdots$ \\
\multirow{J}{\pm}{}
\end{tabular} & î & $\begin{array}{l}\hat{n} \\
\hat{a} \\
\dot{J} \\
\pm\end{array}$ & $\stackrel{\stackrel{0}{i}}{\underset{T}{+}}$ & $\begin{array}{l}\text { Jै } \\
\text { } \\
\dot{J} \\
\dot{J}\end{array}$ & $\underset{\infty}{\infty}$ & $\begin{array}{l}\frac{m}{0} \\
\stackrel{5}{ \pm} \\
\dot{J}\end{array}$ & $\underset{7}{\rightrightarrows}$ & $\begin{array}{l}8 \\
\delta \\
\swarrow \\
\dot{\Xi} \\
\dot{J}\end{array}$ & $\stackrel{\overbrace{}}{\tilde{\gamma}}$ \\
\hline M18 & 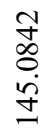 & 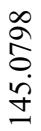 & $\stackrel{ナ}{+}$ & $\begin{array}{l}\hat{a} \\
\hat{0} \\
\stackrel{y}{ \pm}\end{array}$ & $\stackrel{n}{\oplus}$ & 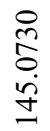 & $\stackrel{\sim}{\sim}$ & 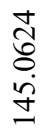 & $\underset{\sim}{\stackrel{\infty}{\sim}}$ & $\begin{array}{l}\dot{0} \\
\dot{0} \\
\dot{0}\end{array}$ & \\
\hline M19 & $\begin{array}{l}\frac{n}{n} \\
\tilde{g} \\
\dot{J}\end{array}$ & 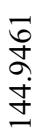 & $\ddot{i}$ & 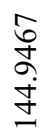 & $\stackrel{\infty}{\stackrel{\infty}{+}}$ & $\begin{array}{l}\stackrel{m}{\Xi} \\
\stackrel{\Xi}{J} \\
\dot{J}\end{array}$ & $\stackrel{2}{\stackrel{1}{1}}$ & 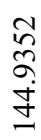 & $\begin{array}{l}\text { ?ֶ. } \\
\stackrel{1}{1}\end{array}$ & $\begin{array}{l}\bar{n} \\
\text { ऽ} \\
\dot{J}\end{array}$ & ث্ণ \\
\hline M20 & $\begin{array}{l}= \\
\infty \\
0 \\
\dot{J} \\
\dot{J}\end{array}$ & 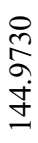 & $\vec{\infty}$ & $\begin{array}{l}\frac{\infty}{\hat{\sigma}} \\
\dot{J}\end{array}$ & $\stackrel{n}{a}$ & $\begin{array}{l}\sqrt{\circ} \\
\circ \\
\dot{J}\end{array}$ & $\stackrel{\stackrel{+}{+}}{\longrightarrow}$ & \begin{tabular}{l}
$n$ \\
$\hat{\sigma}$ \\
\multirow{J}{J}{}
\end{tabular} & $\frac{\infty}{\stackrel{\sim}{i}}$ & 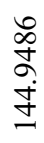 & ñ \\
\hline Bm. 4 & $\begin{array}{l}\stackrel{ }{\sigma} \\
\sigma \\
\ddot{\sigma}\end{array}$ & $\begin{array}{l}\stackrel{\partial}{\circ} \\
\dot{o} \\
\dot{y}\end{array}$ & $\hat{\rho}$ & $\begin{array}{l}\hat{\infty} \\
\stackrel{\sigma}{\sigma} \\
\dot{f}\end{array}$ & $\stackrel{\hat{i}}{\stackrel{\hat{T}}{1}}$ & $\begin{array}{l}\bar{\alpha} \\
\alpha \\
\dot{j}\end{array}$ & $\frac{7}{1}$ & $\begin{array}{l}\overrightarrow{\partial े} \\
\stackrel{0}{a} \\
\dot{J}\end{array}$ & $\stackrel{\overbrace{}}{\sim}$ & $\frac{\stackrel{+}{+}}{\stackrel{\sigma}{+}}$ & $\frac{N}{m}$ \\
\hline
\end{tabular}

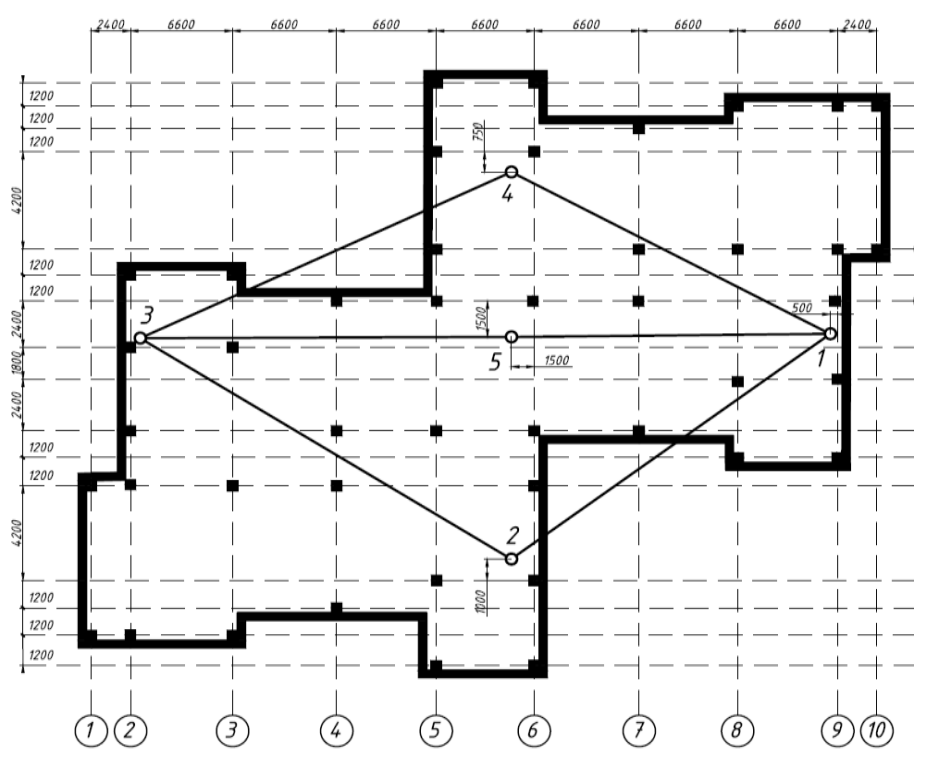

Fig. 1. Plan of a 25 -storey building under construction and a geodetic survey scheme on the initial level. 
The data of analysis of variance of the observation results showed that the displacements of the points of a 12-storey building due to the influence of temperature deformations of its walls when the wall temperature changes from 0 to $16^{\circ} \mathrm{C}$ are characterized by an empirical dispersion of $10.3 \mathrm{~mm}$ and a standard deviation of $3.2 \mathrm{~mm}$.

The dependence of the displacements of the points of a 12-storey building $V_{t}(\mathrm{~mm})$ on changes in the temperature of its walls reflects the corresponding correlation equation:

$$
V_{t}=-0.23+0.37 t-0.008 t^{2}
$$

The influence of temperature deformations of the walls of a 12-storey building with a relative temperature drop of its walls from minus $16^{\circ} \mathrm{C}$ to plus $16^{\circ} \mathrm{C}$ causes errors in the layout work exceeding the SP allowances [12-15].

The values of the empirical coefficient of linear expansion of the walls of a building under construction can vary significantly. According to the results of the studies, for various parts of a 16-storey panel-block building, they range from $2.8 \cdot 10^{-6}$ to $11.7 \cdot 10^{-6}$. Obviously, this is caused by uneven heating of the building walls, including external and internal structures.

For example, the uneven heating of the outer enclosing walls and the supporting inner frame led to the chipping of the outer edges of the hinged panels adjacent in height during the construction of a 25-storey residential building in the Butyrsky Khutor area in Moscow. The destruction began at the end of March, when the night temperature dropped to minus $20^{\circ} \mathrm{C}$. During the day, solar radiation heated the enclosing walls to above-zero temperatures, and the internal load-bearing structures still kept the night cold. According to the project, the horizontal joint between two hinged panels of the building superstructure block should be sealed with a flexible insert, and the underground part - with mortar. But in reality, the joints were everywhere sealed with mortar, which did not compensate for temperature deformations even to a height of $3 \mathrm{~m}$ of two panels adjacent in height.

To take into account the total temperature deformations, it is proposed to determine the corrections to the measured temperature rises using the following formula:

$$
\Delta h=\frac{\Delta_{b}-\Delta_{t}}{h}
$$

where $\left(\Delta_{b}-\Delta_{t}\right)$ - the difference between the empirical coefficients of linear expansion of the walls of the building and the steel tape; $h$-measured excess.

\section{Discussion}

As a result of the study, it was found that the empirical displacements of the points of the building due to changes in the temperature of its walls do not obey the normal distribution law. Obviously, these points receive a systematic shift due to the influence of the above factor. Studies by domestic [16], [17] and foreign [18] authors have shown that both parts of buildings under construction and the building as a whole, and the benchmarks of highrise geodetic survey are subject to vertical displacements. It turned out that such displacements cause systematic errors of high-rise alignment works, characterized by an empirical standard deviation equal to $\pm 8.4 \mathrm{~mm}$, and the residual scattering of random errors is $\pm 2.0 \mathrm{~mm}$ [16]. The prevailing opinion that the influence of displacements of benchmarks and parts of the building are mutually compensated should be considered erroneous. The conducted studies have shown that the effect of displacements of benchmarks and parts of the building on the accuracy of high-rise alignment works exceeds the 2 nd accuracy class during the construction of the 2 nd and higher floors. During the construction of most buildings, the 2nd class of accuracy is adopted, therefore, the effect of displacements of the 
benchmarks of the high-rise base should be taken into account when erecting buildings of 3 or more floors.

Observations showed that the maximum settlings $S$ of the building under construction and the construction area during the installation period reached 40.0 and $1.6 \mathrm{~mm}$, respectively, and uneven settlings were 16.8 and $7.5 \mathrm{~mm}$ (Fig. 1, Table 1). After the construction of the fifth floor, the settling of some points of the earth's surface, on which geodetic signs are located, changed to an upward movement. The uneven settling of the building during the installation of the entire frame caused displacement of the columns up to $19.9 \mathrm{~mm}$ (Fig. 2, Table 2) in the plan after their installation in the design position. A very important conclusion follows from the above that uneven settling of a building during its construction cause horizontal displacements of its elements. The heeling of the building due to the uneven settling of the base has a significant effect on the verticality of the walls of the elevator shafts. According to the requirements of regulatory documents, deviations of the walls of these shafts from the vertical should not exceed $30 \mathrm{~mm}$ only in the direction of widening. The allowance includes the errors of certain factors that affect the accuracy of installation work.

Table 2. Displacement of columns due to uneven settling.

\begin{tabular}{|c|c|c|c|c|c|c|c|c|c|c|c|c|c|}
\hline \multirow{4}{*}{$\begin{array}{c}\text { Cycle } \\
\text { No. }\end{array}$} & \multirow{4}{*}{$\begin{array}{c}\text { Building } \\
\text { height }\end{array}$} & \multicolumn{12}{|c|}{ Column displacement } \\
\hline & & \multicolumn{6}{|c|}{ across the building } & \multicolumn{6}{|c|}{ along the building } \\
\hline & & \multicolumn{12}{|c|}{ columns of the floor } \\
\hline & & 1 & 5 & 9 & 13 & 20 & 26 & 1 & 5 & 9 & 13 & 20 & 26 \\
\hline 1 & 3 & $\stackrel{0}{0}$ & & ' & ' & ' & 1 & $\stackrel{\circ}{\circ}$ & ' & 1 & ' & ' & \\
\hline 2 & 20 & $\stackrel{\infty}{0}$ & $\stackrel{\infty}{0}$ & ' & 1 & ' & ' & サ. & $\stackrel{0}{0}$ & ' & ' & ' & \\
\hline 3 & 32 & $\stackrel{n}{7}$ & $\stackrel{+}{+}$ & $\stackrel{0}{0}$ & ' & ' & ' & $\hat{i}$ & $\vec{i}$ & $\stackrel{0}{0}$ & 1 & 1 & ' \\
\hline 4 & 44 & n़ & $\stackrel{+}{+}$ & $\stackrel{\check{0}}{\bar{T}}$ & $\stackrel{0}{0}$ & ' & ' & $\stackrel{+}{+}$ & $\ddot{n}$ & $\frac{\infty}{\not}$ & $\stackrel{\circ}{\circ}$ & ' & \\
\hline 5 & 65 & $\stackrel{1}{1}$ & $\vec{i}$ & $\stackrel{n}{t}$ & $\ddot{a}$ & $\stackrel{0}{\circ}$ & ' & ㄱ. & $\begin{array}{l}0 \\
\dot{1}\end{array}$ & $\stackrel{\pi}{i}$ & $\frac{\partial}{t}$ & $\stackrel{\circ}{\circ}$ & \\
\hline 6 & 84 & $\grave{q}_{1}$ & ?? & $\begin{array}{l}n \\
0 \\
+\end{array}$ & $\ddot{i}$ & $\begin{array}{l}0 \\
\dot{0}\end{array}$ & $\stackrel{\circ}{\circ}$ & 욱. & $\stackrel{\infty}{i}$ & $\tilde{i}$ & $\underset{\infty}{\sim}$ & ? & $\stackrel{0}{0}$ \\
\hline
\end{tabular}



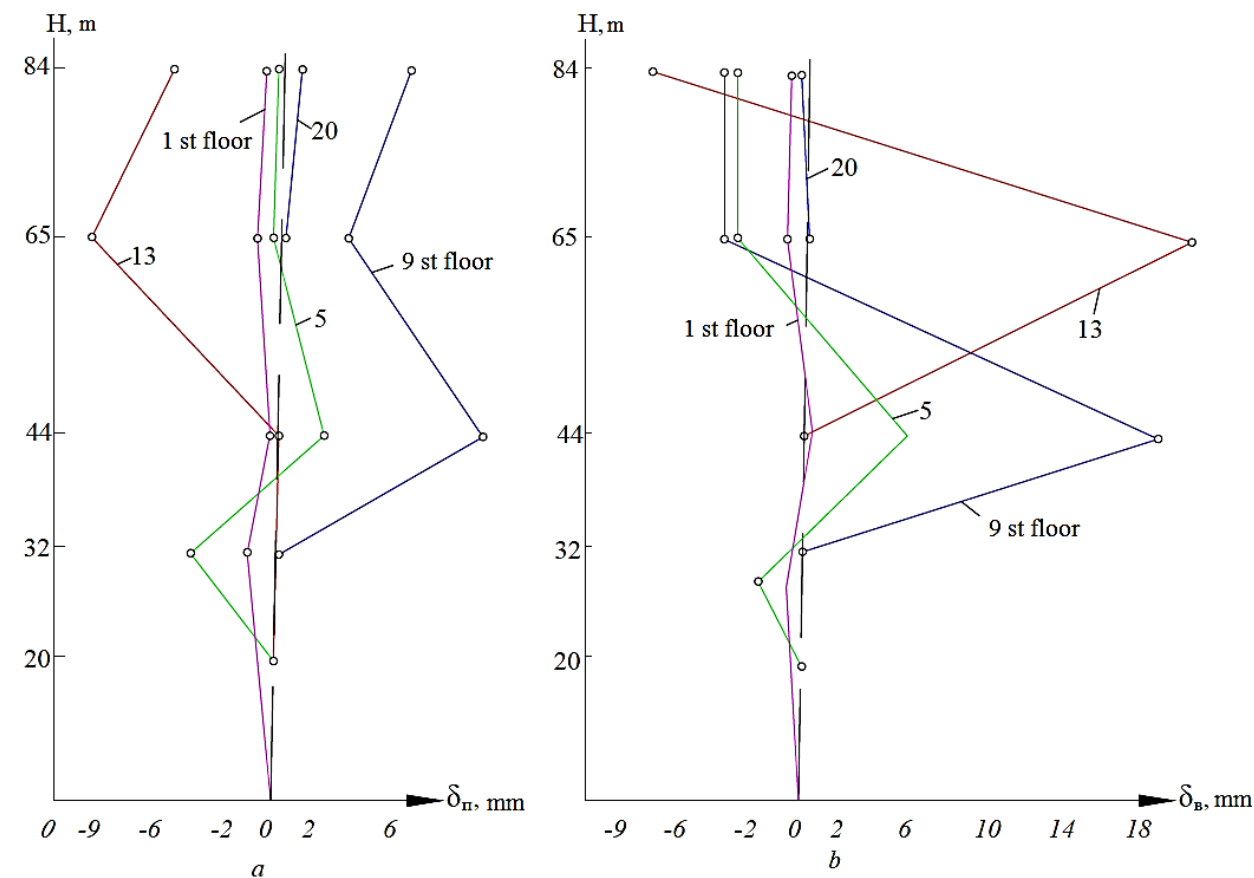

Fig. 2. The graph of displacement of columns of $1^{\text {st }}, 5^{\text {th }}, 9^{\text {th }}, 13^{\text {th }}$, and $20^{\text {th }}$ floors in the plan: $a$ - across the building; $b$ - along the building. Vertical axes - building height $H$, $\mathrm{m}$; horizontal axes displacement of columns across $\left(\delta_{\mathrm{ac}}, \mathrm{mm}\right)$ and along $\left(\delta_{\mathrm{al}}, \mathrm{mm}\right)$ the building.

It is usually believed that the verticality of the walls of elevator shafts depends only on three main factors: inaccuracies of the alignment work; inaccuracies in installation work; deviations made in the manufacture of prefabricated elements. The influence of uneven settling is usually not taken into account. However, practice has shown that the walls of elevator shafts can receive excess deviations from the vertical only due to uneven settlement of the corners of the building being erected. For example, the uneven settling of a 16-storey building measuring $19.72 \times 19.40 \mathrm{~m}$ in plan and $45 \mathrm{~m}$ high reached almost 30 $\mathrm{mm}$ (Fig. 3) and caused deviations in the verticality of the walls of around $60 \mathrm{~mm}$. This heeling significantly exceeds the regulatory allowance, which is assigned taking into account all of the above factors.

\section{Conclusions}

During construction of most buildings and structures, settling observations are usually not carried out. However, for the correct organization of geodetic measurements and the identification of objective reasons for deviations from the vertical of the walls of elevator shafts and supporting structures, it is necessary to observe the settlings of all buildings and structures. The question of the need for them must be decided taking into account the expected values of the building's settling and heeling. The latter can be calculated before the start of construction, for example, during the period of drawing up a project for the production of geodetic works, using well-known methods [12]. According to the calculation of the expected settling, it is easy to determine the expected maximum heeling of the building using the well-known formula: 


$$
K=\frac{\Delta S H}{L},
$$

where $S$ - maximum difference in settling of corresponding corners of the building, $\mathrm{mm}$;

$H$ - building height, in $\mathrm{m}$;

$L$ - distance between the corners of the building, in the direction of one of which the expected heeling is determined, $\mathrm{mm}$.

A very important conclusion follows from the above: when designing buildings, it is necessary to determine the expected heeling of buildings, and if this is not done, then such a calculation must be performed before starting construction. If calculations show that it will be of the order of $20 \mathrm{~mm}$ or more, then the design and construction organization should take measures in advance to comply with the established requirements when installing lift equipment in the corresponding shafts.

Thus, in the article, using specific examples, the need to measure the actual quantitative values characterizing changes in the design geometry of buildings and structures during their construction and operation for subsequent forecasting is shown. This will contribute to the safety of the structures of these objects. The authors hope that the article will be useful for surveyors.

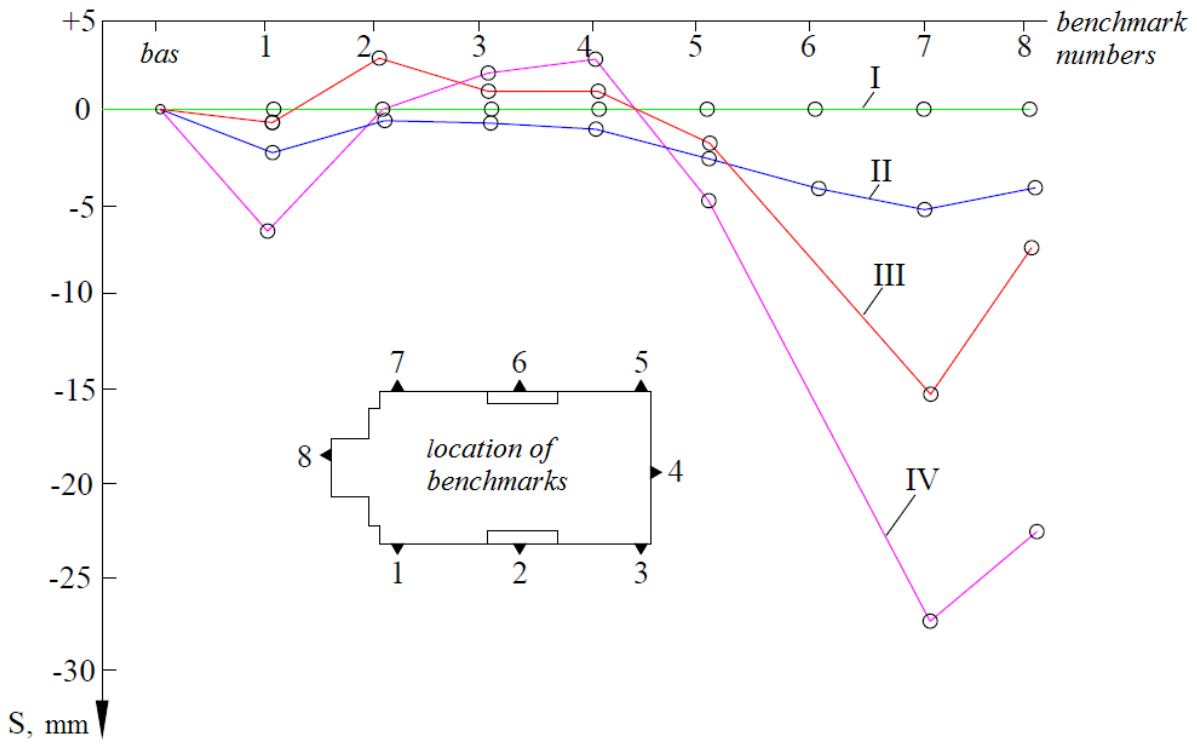

Fig. 3. The graph of the settlings $S$ (vertical axis) of the benchmarks and the scheme of their location:

I, II, III and IV - leveling cycles.

\section{References}

1. P.I. Bright, E.N. Medvetskiy, Measurement of deformation settlings of structures by geodetic methods (M., Geodezizdat, 1959)

2. E.B. Klyushin, M.I. Kiselev, D.Sh. Mikhelev et al., The engineering geodesy (M., Academy, 2004)

3. G.A. Dzhinchvelashvili, Industrial and civil engineering 9, 17-21 (2011)

4. Climate and the City: Proceedings of the All-Union Interdepartmental Conference "Climate - City-Man" (Moscow, Knowledge, 1974) 
5. N.G. Viduev, Yu.V. Polishchuk, Engineering Geodesy 6, 18-26 (1969)

6. A.G. Tamryazyan, S.G. Yesayan, Concrete creep mechanics (M., MGSU Publishing House, 2012)

7. B.G. Bogdanov, Geodesy and Cartography 4, 2629 (1973)

8. A.K. Pevnev, A.Ya. Chernikov, Geodesy and Cartography 5, 16-24 (2004)

9. I.I. Entin, Geodesy and Cartography 2, 8-13 (1970)

10. V.D. Kopylov, Kui Dyk Nguyen, Industrial and civil engineering 9, 43- 45 (2011)

11. G.I. Romanus, Geodesy and Cartography 1, 24-27 (1971)

12. SP 22.13330.2011. Foundations of buildings and structures (M., 2011)

13. B. Kovačič, R. Kamnik, A. Pustovgar, N. Vatin, Analysis of Precision of Geodetic Instruments for Investigating Vertical Displacement of Structures, Procedia Eng. 165 906-917 (2016) https://doi.org/10.1016/j.proeng.2016.11.800.

14. B. Kovačič, R. Kamnik, N. Vatin, A. Ishkov, The Vertical Displacement Measurement of Concrete Plates with Special Emphasis on Rough Error, Procedia Eng. 165 936-946 (2016) https://doi.org/10.1016/j.proeng.2016.11.803.

15. B. Kovačič, R. Kamnik, V. Solovev, N. Vatin, The Comparison of Measuring and Computing Results of Construction Vertical Displacement, Procedia Eng. 165 926-935 (2016) https://doi.org/10.1016/j.proeng.2016.11.802.

16. N.A. Shmelin, Geodesy and Cartography 1, 35 - 39 (1975)

17. P.I. Bright, Proceedings of the IV Congress of the All-Union astr. and geod. assoc. (M., "Nauka", 1970)

18. D. Maas, Vermessungstechnik 5(20.10), 168 -171 (1973) 